\title{
Exploiting the Interplay between Liquid-Liquid Demixing and Crystallization of the PVDF Membrane for Membrane Distillation
}

\author{
N. I. M. Nawi, ${ }^{1}$ M. R. Bilad ${ }^{D},{ }^{1,2}$ N. A. H. M. Nordin, ${ }^{1}$ M. O. Mavukkandy, ${ }^{3}$ Z. A. Putra, ${ }^{1}$ \\ M. D. H. Wirzal ${ }^{D},{ }^{1}$ J. Jaafar ${ }^{D},{ }^{4}$ and Asim L. Khan ${ }^{5}$ \\ ${ }^{1}$ Chemical Engineering Department, Universiti Teknologi PETRONAS, Bandar Seri Iskandar, 32610 Perak, Malaysia \\ ${ }^{2}$ Jurusan Pendidikan Kimia, Institut Keguruan Ilmu Pendidikan, Jalan Pemuda No 59A, Mataram, Indonesia \\ ${ }^{3}$ Institute Center for Water and Environment (iWater), Department of Chemical and Environmental Engineering, Masdar Institute, \\ Khalifa University of Science and Technology, PO Box 54224, Abu Dhabi, UAE \\ ${ }^{4}$ Advanced Membrane Technology Research Centre (AMTEC), Faculty of Chemical and Natural Resources Engineering, \\ Universiti Teknologi Malaysia, 81310 Skudai, Johor, Malaysia \\ ${ }^{5}$ Department of Chemical Engineering, COMSATS Institute of Information Technology, Lahore, Pakistan
}

Correspondence should be addressed to M. R. Bilad; mroil.bilad@utp.edu.my

Received 12 July 2018; Accepted 10 September 2018; Published 5 December 2018

Academic Editor: Hossein Roghani-Mamaqani

Copyright (C) 2018 N. I. M. Nawi et al. This is an open access article distributed under the Creative Commons Attribution License, which permits unrestricted use, distribution, and reproduction in any medium, provided the original work is properly cited.

\begin{abstract}
Membrane distillation (MD) purifies water by transporting its vapor through a hydrophobic membrane. An ideal MD membrane poses high water flux and high fouling, scaling, and wetting resistances. In this study, we develop polyvinylidene fluoride (PVDF) membranes for MD by focusing on reduction of PVDF degree of crystallinity. We explore the roles of dope solution temperature in dictating the phase separation mechanisms as well as the structure and the performance of semicrystalline PVDF membranes. DSC spectra show that higher dope solution temperature depresses crystallinity via formation of imperfect crystal. Such findings were also supported by FTIR and XRD results. The SEM images reveal formation of spherulite-like morphology in the membrane matrices for membranes prepared from high temperature dope solutions. A good balance between solid-liquid and liquid-liquid phase separations that offers low degree of crystallinity was found at a dope solution temperature of $60^{\circ} \mathrm{C}$ (PVDF-60), which showed the MD flux of $18 \mathrm{l} / \mathrm{m}^{2} \mathrm{~h}$ (vs. $6 \mathrm{l} / \mathrm{m}^{2} \mathrm{~h}$ for temperature of $25^{\circ} \mathrm{C}$, as a benchmark) and nearly complete salt rejection when run at hot and cold temperatures of $65^{\circ} \mathrm{C}$ and $25^{\circ} \mathrm{C}$, respectively. The PVDF- 60 shows a high wetting resistance and stable MD flux of $10.5 \mathrm{l} / \mathrm{m}^{2} \mathrm{~h}$ over a $50 \mathrm{~h}$ test for treating brine solution as the feed $(70 \mathrm{~g} \mathrm{NaCl} / \mathrm{l})$.
\end{abstract}

\section{Introduction}

Membrane distillation (MD) is an emerging technology that, under correct circumstances, can play important roles in solving the water scarcity issue. MD exploits the vapor pressure difference between the hot feed and the cold permeate to drive water vapor transport across a hydrophobic membrane. The membrane is selective to water vapors, but thanks to its hydrophobic property, it repels liquid water and other nonvolatile solutes including salts. The passing water vapor condenses at the cold side as permeate.

The ideal MD membrane should facilitate high flux, high salt rejection, high wetting resistance, low scaling and fouling, and low thermal conductivity [1]. High flux can be achieved by having the membrane with large enough pore size (not too large to maintain high liquid entry pressure, LEP: a minimum required pressure for water to penetrate through the membrane), high bulk porosity, abundant surface pore, and low tortuosity factor and a thin membrane. Wetting resistance can be improved by having the membrane with high hydrophobicity and small bubble point (BP, maximum pore size). The pore size distribution (PSD) must be narrow and the median pore must be close to the BP to obtain both high wetting resistance and high flux.

Membrane surface hydrophobicity is achieved by using materials of low surface energy (i.e., fluorinated). A low 
surface energy material facilitates a high water LEP. The indicators for determining membrane surface hydrophobicity include water contact angle (CA) and BP, as ascribed by the Laplace equation [2]. Meanwhile, a highly hydrophobic membrane also helps to increase scaling and fouling resistances. Membrane fouling refers to deposition of a particle or mineral, all referred as foulant, on the surface of the membrane surface blocking and plugging the pore mouth. Plugging then declines and diminishes the water vapor flux and lowers permeate quality by depressing the salt rejection or even promotes membrane wetting when applied for desalination [3]. Heat loss via conduction, despite often seen as the least concern, can be reduced by opting for materials with low thermal conductivity or generating thick and porous membranes $[4,5]$. In $\mathrm{MD}$, heat transfers through both pores and membrane matrix from feed to the permeate side; thus, employing a thin and conductive membrane may cause great conductive heat losses. Severe heat transfer from the hot to the cold side can decrease flux because of loss in driving force.

Substantial research focuses on development of a polyvinylidene fluoride- (PVDF-) based membrane for MD. The PVDF polymer has a good chemical resistance, a high thermal stability, and excellent structural matrices [6]. It also poses outstanding morphologies which facilitate formation of permeable and highly porous films [1]. Currently, PVDF polymers have extensively been used as material for the MD membrane and other porous-based membrane applications [6].

Recent researches on the PVDF membrane for MD focus on development of highly hydrophobic materials. Although PVDF poses a relatively low surface energy, a phase-inverted one from a strong nonsolvent (i.e., water) usually has low hydrophobicity [7]. The low CA originates from the absence of the lotus effect. As reported by Peng et al. [8], hydrophobicity is promoted by combination of both micro- and nanoscales onto the membrane surface. Application of either strong solvent or strong nonsolvent in the phase inversion flattens the membrane surface and reduces the surface CA.

Controlling water vapor supply from humid air in vaporinduced phase separation (VIPS) has been proven to reduce the extent of flattening effect [7]. In this approach, the immediate contact of the film surface with water can be evaded. Moreover, employing very low PVDF concentrations using the VIPS technique may produce a super hydrophobic surface $\left(\mathrm{CA}>140^{\circ}\right)$ which has a discontinuous hierarchical structure due to the occurrence of spinodal decomposition during phase separation [9]. Regardless of the discontinuous structure, crystallization also contributes to nanoscale roughness in the morphology of the surface [10]. This will eventually increase surface CA and hydrophobicity of the membrane if the crystals reside on the membrane surface, as reported elsewhere [7].

As a semicrystalline polymer, crystallization of the PVDF polymer also occurs during membrane formation via phase inversion. It occurs at a relatively slower rate relative than the liquid-liquid demixing. The degree of PVDF crystallization can be altered by manipulating phase inversion parameters, in particular by selection of a nonsolvent type and adjusting its temperature [11]. The type and the shape of PVDF crystals can be manipulated by changing bath temperature [12] or by selecting a weak nonsolvent that hinders liquid-liquid demixing and thus allows higher extent of crystallization.

The membrane with a low crystallinity is desirable to improve overall porosity and its hydraulic performance. To our best knowledge, limited study explores the role of PVDF crystallinity in its MD performance. Our previous study only focuses on the effect of dope solution temperature on the structure and short-term performance of MD membranes [13]. This study exploits semicrystalline behavior of the PVDF polymer to develop PVDF membranes and evaluate their MD performances in short- and long-term tests. We manipulate the dope solution temperature to lower its degree of crystallinity. It is hypothesized that high dope solution temperature increases the rate of solvent and nonsolvent exchanges to expedite liquid-liquid demixing and restrict crystallization. Five PVDF membranes were prepared, 25, $40,60,80$, and $100^{\circ} \mathrm{C}$ of dope solutions, further referred to as PVDF-25, PVDF-40, PVDF-60, PVDF-80, and PVDF100 , respectively, via the phase inversion. The resulting membranes were thoroughly characterized, and their performances were assessed by treating simulated seawater and brine in short- and long-term direct contact membrane distillation (DCMD) tests.

\section{Methods}

2.1. Membrane Preparation. To prepare the phase-inverted PVDF membranes, PVDF (534 kDa, Sigma-Aldrich), dimethylacetamide (DMAC, Sigma-Aldrich), and deionized water were used as polymer, solvent, and nonsolvent, respectively. The summary of the prepared membranes and their respective codes is given in Table 1 . The dope solution was prepared by stepwise dissolution of $15 \% w / w$ of PVDF into DMAC. The polymer concentration was selected as an optimum value obtained from [14]. The dopes were simultaneously stirred and heated at $25,40,60,80$, and $100^{\circ} \mathrm{C}$ until they were homogeneous. To ensure thorough dissolution, the stirrings were done at least for $24 \mathrm{~h}$ at $150 \mathrm{rpm}$, followed by degassing to achieve bubble-free solutions. Each of them was then casted atop a nonwoven support (NWS, Novatexx 24413, Freudenberg-filter, Germany) using a casting blade at a wet thickness of $0.240 \mathrm{~mm}$. After casting, the cast films were immediately immersed in a DI bath at $25^{\circ} \mathrm{C}$. The solidified film was then maintained in the coagulation bath overnight to ensure complete removal of solvent followed by drying at room temperature.

2.2. Membrane Characterization. The membrane thickness of each sample was measured (at least at 5 locations) using a micrometer (Mitutoyo, Japan). The membrane pore size including mean pore size (MPS), BP, and PSD was determined using capillary flow porometer (CFP, Porous Materials Inc. Ithaca, USA). Porosity of each samples was measured gravimetrically using the dry-wet method. Fourier transform infrared spectrometer (FTIR) in the mode of attenuated total 
TABLE 1: Summary of the developed PVDF membrane properties.

\begin{tabular}{|c|c|c|c|c|c|}
\hline \multirow{2}{*}{ Membrane code } & \multirow{2}{*}{ Dope solution temperature $\left({ }^{\circ} \mathrm{C}\right)$} & \multirow{2}{*}{ Thickness $(\mu \mathrm{m})$} & \multirow{2}{*}{ Porosity (\%) } & \multicolumn{2}{|c|}{ Contact angle $\left({ }^{\circ}\right)$} \\
\hline & & & & Top & Bottom \\
\hline PVDF-25 & 25 & $333.0 \pm 5.3$ & $83.2 \pm 0.4$ & $77.4 \pm 1.8$ & $104.6 \pm 3.5$ \\
\hline PVDF-40 & 40 & $280.4 \pm 8.6$ & $78.0 \pm 1.1$ & $77.2 \pm 3.3$ & $113.8 \pm 8.4$ \\
\hline PVDF-60 & 60 & $250.2 \pm 6.1$ & $73.3 \pm 1.1$ & $80.4 \pm 3.0$ & $121.8 \pm 4.1$ \\
\hline PVDF-80 & 80 & $265.8 \pm 6.9$ & $76.0 \pm 1.0$ & $82.8 \pm 3.7$ & $120.2 \pm 7.3$ \\
\hline PVDF-100 & 100 & $276.0 \pm 10.0$ & $77.5 \pm 1.3$ & $75.6 \pm 6.1$ & $114.2 \pm 4.1$ \\
\hline
\end{tabular}

TABLE 2: Heat of fusion and degree of crystallinity of the developed PVDF membranes.

\begin{tabular}{lcc}
\hline Membrane code & $\begin{array}{c}\text { Heat of fusion, } \\
\Delta H_{f}(\mathrm{~J} / \mathrm{g})\end{array}$ & $\begin{array}{c}\text { Degree of crystallinity, } \\
X_{c}(\%)\end{array}$ \\
\hline PVDF-25 & 54.37 & 51.93 \\
PVDF-40 & 48.97 & 46.77 \\
PVDF-60 & 46.87 & 44.77 \\
PVDF-80 & 48.01 & 45.85 \\
PVDF-100 & 49.20 & 46.77 \\
\hline
\end{tabular}

reflection (ATR) was used to study the chemical bonds of the membrane samples. The measurements were done at wavenumbers ranged from 650 to $4000 \mathrm{~cm}^{-1}$. The morphology of the membranes was obtained by a scanning electron microscopy (SEM, Quanta-250, FEI) on the cross section and top surface. To obtain a representative cross section structure, the samples were cut under liquid nitrogen before they were coated with gold and palladium at $50 \AA$ to avoid overcharging. The CA was measured using goniometer and the membrane surface using sessile drop of $7 \mu \mathrm{l}$ (5 replicates). An X-ray diffraction (XRD) was used to investigate the type of PVDF crystals in the membrane matrix. Differential scanning calorimeter (DSC) was used to evaluate crystallinity degree of the PVDF. The heat of fusion and total crystallinity of the developed membranes were summarized in Table 2. Heat of fusion was obtained by integrating the area under the DSC curves. Total crystallinity, $X_{c}$ of PVDF, was calculated by using the following formula [15]:

$$
X_{c}=\frac{\Delta H_{f}}{\Delta H_{f}{ }^{*}} \times 100 \% \text {, }
$$

where $\Delta H_{f}{ }^{*}$ is the melting enthalpy for $100 \%$ crystalline PVDF $(104.7 \mathrm{~J} / \mathrm{g})$ and $\Delta H_{f}$ is the melting enthalpy of samples obtained from DSC.

2.3. DCMD Set-Up and Operational Parameter. A lab-scale DCMD set-up (Figure 1) was used to evaluate membrane performance. It consisted of a filtration cell in which both feed and permeate were flown at a fixed crossflow velocity of $2.22 \mathrm{~cm} \mathrm{~s}^{-1}$. The system was fed using $65^{\circ} \mathrm{C}$ of synthetic seawater (comprising of $3.5 \mathrm{wt} \% \mathrm{NaCl}$ in DI water) and brine (comprising of $7.0 \mathrm{wt} \% \mathrm{NaCl}$ in DI water) coupled with $25^{\circ} \mathrm{C}$ distilled water as the cold stream. The flux was collected as an overflow, and the weight was measured using a high precision weighing balance.

To study the performance stability and wetting resistibility of the samples, a long-term DCMD test $(50 \mathrm{~h})$ was conducted for a selected membrane (the PVDF-60 that shows the best performance in the short-term test). The simulated brine solution was used as the feed, which was fed at temperature of $65^{\circ} \mathrm{C}$. DI water fed at temperature of $25^{\circ} \mathrm{C}$ was used as the cold stream in the permeate side. The conductivity of permeate was periodically measured every 1 hour during the operation to calculate the salt rejection involving salt balance calculation.

\section{Results and Discussion}

\subsection{Effect of Dope Solution Temperature on Membrane Properties}

3.1.1. Contact Angle. The selected properties of the PVDF membranes, including top layer CA, bottom layer CA, membrane thickness, MPS, porosity, and BP, are shown in Table 1. Results show that temperature of dope solution does not affect the CA of the resulting membranes. The CA values of the top $\left(75.6-82.8^{\circ}\right)$ are much lower than the bottom surfaces $\left(104.6-121.8^{\circ}\right)$. The top surface CAs are also relatively low compared to [7] but still fall within reported values using the same systems (employing strong solvent and nonsolvent) reported elsewhere [16].

The low CA of the top membrane surface is largely a result of surface flattening effect as shown by the surface SEM images (Figure 2). Flattening effect refers to the polymer chain mobility atop the cast film as a result of a large interfacial tension gap between the cast film and water (nonsolvent). Such a large gap forces the polymer chain to move downwards into the bulk. This leads to formation of a flat and smooth surface contributing in lowering the CA [17]. A flat surface reduces the presence of structural features and thus depresses hydrophobicity [7, 18]. Despite being categorized as hydrophilic $\left(\mathrm{CA}<90^{\circ}\right)$, such membranes can still be employed in MD because the sublayers under the top skin are much more hydrophobic (see CA value of the bottom surface), as also proven in Sections 3.2 and 3.3. As demonstrated by the cross section image, a morphology like the bottom surface is expected across the PVDF matrix, except for the one on the top surface.

3.1.2. Thickness, Porosity, and Pore Size. The resulting membrane morphology can explain the effect of dope solution 


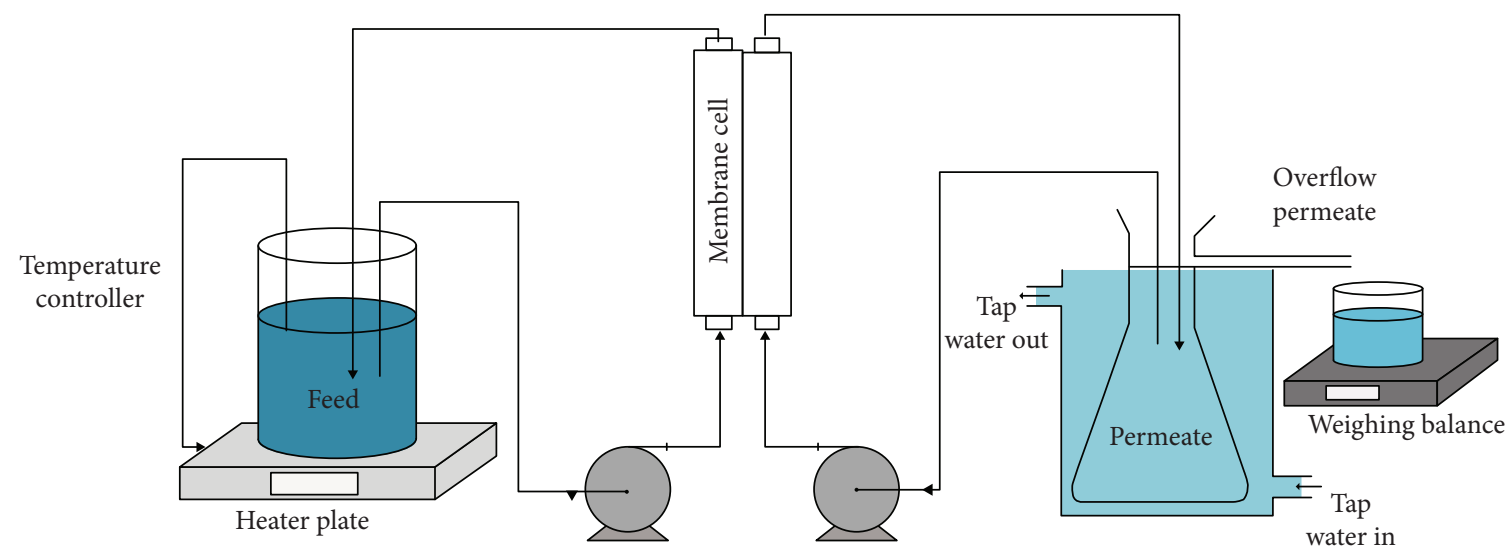

Figure 1: Experimental set-up for direct contact membrane distillation.
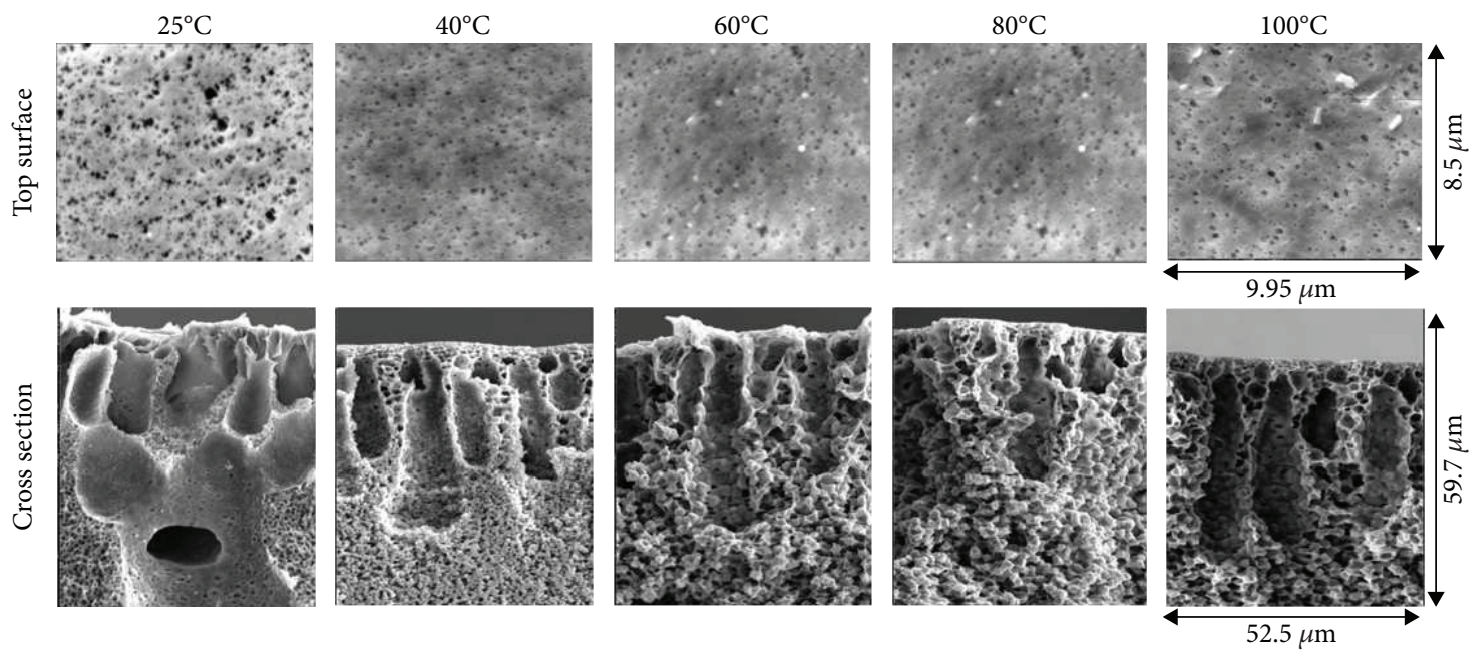

FIgURE 2: SEM images of the PVDF membranes (magnification: 30,000x).

temperature on thickness, porosity, and pore size. The dope solution temperature dictates the type of the crystalline phase that constructs the membrane matrix $[11,19]$. Membrane thickness is greatly reduced as the dope solution temperature is increased (from $333 \mu \mathrm{m}$ for the PVDF-25 to 250.2-280.4 $\mu \mathrm{m}$ for the rest) but has less prominent effect on the porosity (Table 1). Higher temperatures reduce the size of macrovoids underneath the top skin layer. This can be explained by reduction of solution viscosity that, at high temperature, facilitates exchange of solvent and nonsolvent during phase separation. Increasing the dope solution temperature accelerates the dissolution of solvent, which also explains why the membrane is thinner. The faster the speed of the double diffusion, the faster is the membrane formation rate [20], which makes the macrovoid structure not have enough time to develop. Therefore, the sizes of macrovoids are relatively small.

The trend on overall porosity can be explained as below. The overall structure of the membrane matrix can be distinguished as macrovoid and sponge or particulatelike morphology. For the membrane with large macrovoid (PVDF-25), the porosity of the sponge-like region is low and thus compensate the large space contributed by the macrovoids. On the other hand, there is only a lower contribution of smaller macrovoid to overall porosity, due to their smaller sizes (Figure 3). For higher dope solution temperature $\left(>25^{\circ}\right)$, they are compensated by large contribution of spherulite-like zone in the matrix.

Figure 3 shows the PSD of the PVDF-100, PVDF-60, and PVDF- $25^{\circ} \mathrm{C}$ with their BP of $0.153,0.139$, and $0.989 \mu \mathrm{m}$ and MPS of $0.099,0.138$, and $0.238 \mu \mathrm{m}$, respectively. PVDF-25 also shows larger size of pore mouths from the SEM images of the membrane surface (Figure 2). For PVDF-40, PVDF60 , and PVDF-100, the pore sizes have insignificant differences. However, the surface pore of PVDF-100 has larger size, but the size is still smaller than PVDF-25.

Increasing the temperature of dope solution decreases the MPS and BP because higher temperature accelerates exchange of solvent and nonsolvent. Rapid exchange of solvent/nonsolvent results in rapid formation of the solidified top skin layer. The solidification process is so fast, as such, the expansion of pore nucleus that manifests the polymer lean-phase is restricted thus depressing the surface pore. Instantaneous liquid-liquid demixing also suppresses macrovoids, which then restrict expansion of the cast firm to form a thinner membrane (Table 1), as discussed earlier. It is worth 


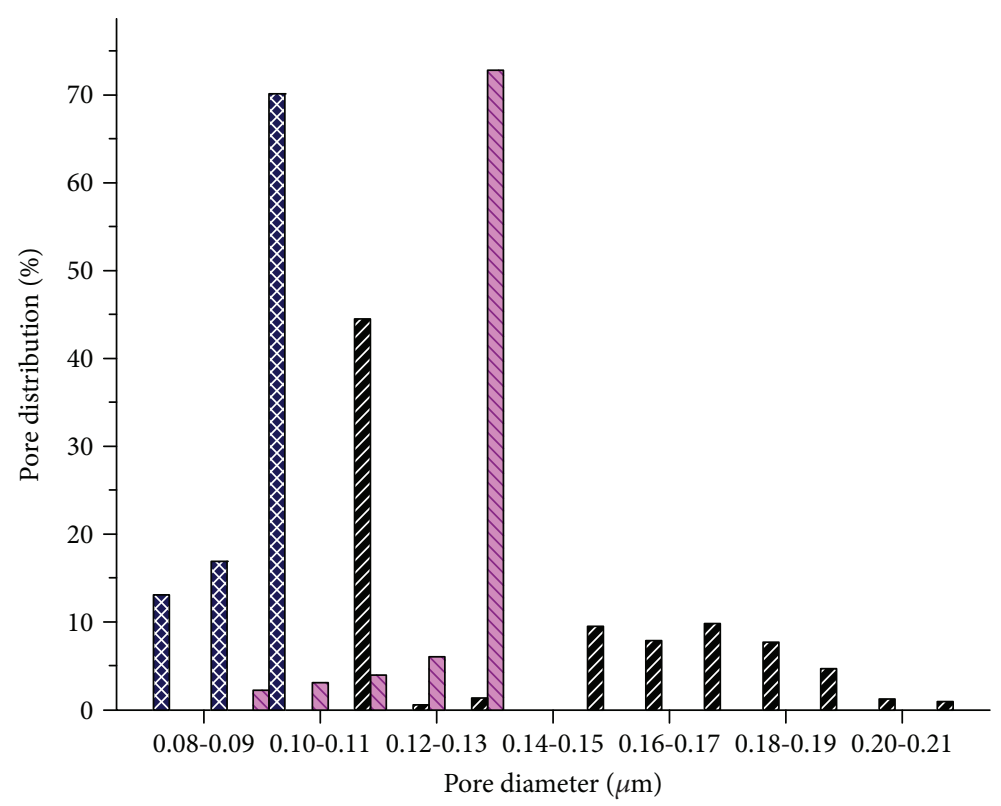

PVDF-25

PVDF-60

PVDF-100

FIgURe 3: Pore size distribution of PVDF-25, PVDF-60, and PVDF-100.

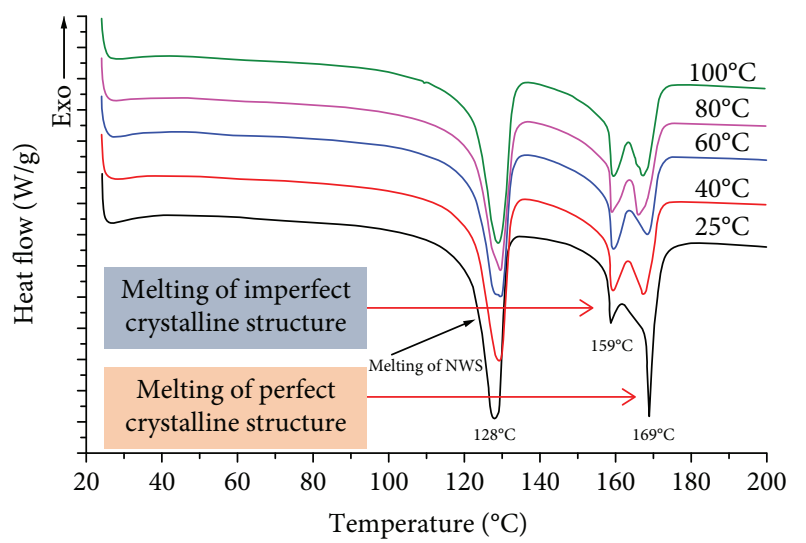

FIGURE 4: Differential scanning calorimeter (stacked) curves of PVDF membranes cast from different dope solution temperatures.

noting that majority of pore sizes (about $80 \%$ ) have values close to BP, as showed by PVDF-60. Such profile promotes water vapor flux, and since the BP-value is small, it enhances wetting resistance, a desired $\mathrm{MD}$ membrane property.

3.1.3. Morphology. Figure 2 shows the effect of dope solution temperatures on the morphologies of the membrane surface (first row) and cross section (second row). Surface SEM images show quite smooth and flat topology, a result of the flattening effect as discussed earlier.

The cross section morphology is clearly affected by dope solution temperature (Figure 2). There is no spherulite-like structures over the cross section of the PVDF-25. This membrane poses large macrovoids underneath the top layer, sandwiched by sponge-like morphology below them. The spherulite-like structures are only formed in the matrices of
PVDF-40, PVDF-60, and PVDF-100. The size of the spherulite-like structure increases toward PVDF-60 and remains almost the same at higher dope solution temperature (PVDF-80 and PVDF-100). The spherulite-like structure is believed to be the imperfect crystals from the semicrystalline PVDF, as also suggested from DSC results (Section 3.1.4). The cross-sectional images also show that they only exist underneath the top skin layer, leaving the top surface in flat topology.

3.1.4. Crystallinity. The PVDF membranes prepared from high temperature dope solution have lower degree of crystallinity with different crystal morphologies as shown from DSC curves in Figure 4. This occurs because of the more rapid demixing process. High cast film temperature reduces viscosity and facilitates faster exchange of solvent and nonsolvent during phase inversion. Such situation leads to overwhelming effect of liquid-liquid demixing and hence curbs crystallization.

The first peak at $128^{\circ} \mathrm{C}$ indicates the melting of NWS used as baking material for membrane fabrication. Two peaks at temperatures of 159 and $169^{\circ} \mathrm{C}$ indicate the melting point of the PVDF polymer. The coexistence of two peaks at these temperatures occurs because of the different crystalline phases that coexist in the membrane matrix $[15,19]$. The peak at $159^{\circ} \mathrm{C}$ represents the melting of the imperfect crystalline region, while the melting of the perfect region occurs at $169^{\circ} \mathrm{C}$. Imperfect crystallization is facilitated by a rapid liquid-liquid demixing and solidification process. Fast demixing, in combination with rapid solidification of the top film, restricts expansion of the cast film to upper direction. Under such circumstances, rearrangement of PVDF chain during crystallization is thus limited. 


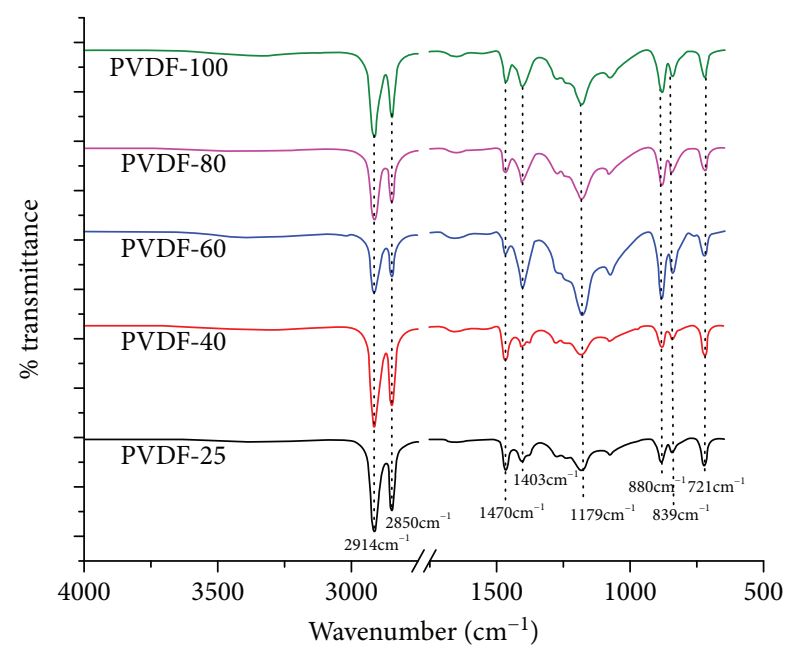

FIGURE 5: Fourier transform infrared spectroscopy-attenuated total reflectance (stacked) spectra of PVDF membranes casted from different dope solution temperatures of $25,40,60,80$, and $100^{\circ} \mathrm{C}$ for PVDF-20, PVDF-40, PVDF-60, PVDF-80, and PVDF100 , respectively.

PVDF-25 shows that majority of the crystal consists of a perfect crystalline structure. Lower dope solution temperature (i.e., $25^{\circ} \mathrm{C}$ ), despite being categorized as instantaneous demixing, provides ample time for formation of perfect crystal during phase inversion. Remarkably, when comparing all samples prepared from heated dope solutions (PVDF-40 to PVDF-100), all membranes have similar peak intensities at temperatures of 159 and $169^{\circ} \mathrm{C}$, except the PVDF-60 that shows higher peak ascribed for the peak for imperfect crystalline. Such variations in the crystal structure may affect mass transport resistance of the membrane (as discussed in Sections 3.2 and 3.3), as well as thickness, porosity, and pore size.

Among four membranes prepared at the temperature range of $40-100^{\circ} \mathrm{C}$, PVDF-60 shows the lowest degree of crystallinity (Table 2). This can be explained by the variable rate of demixing across the cast film thickness. There are two major factors affecting liquid-liquid demixing and crystallization. High temperature leads to rapid solvent and nonsolvent exchanges from and to the cast film which also fasten the solidification of the top skin layer, resulting in a membrane with low crystallinity [21]. However, when the temperature is too high, skin layer formation occurs so fast that it inhibits further solvent and nonsolvent exchanges for the bottom layer of the cast film to allow crystallization. Those phenomena lead to an optimum condition at a temperature of about $60^{\circ} \mathrm{C}$. Under this temperature, the solvent and nonsolvent exchange rates are fast enough to suppress crystallization but insufficient to hinder further solvent and nonsolvent exchanges from the lower part of the cast film.

The crystallinity behaviors of PVDF matrix in membranes prepared from different dope solution temperatures are also visible in the FTIR-ATR spectra (Figure 5). All membranes have identical peak locations ranging from 720 to $2915 \mathrm{~cm}^{-1}$, but those peaks have distinct differences in intensities. There are strong absorption bands at 721, 839, and $880 \mathrm{~cm}^{-1}$ corresponding to $\mathrm{C}-\mathrm{H}$ rocking and $\mathrm{C}-\mathrm{F}$ stretching vibration of PVDF, respectively. The presences of the absorption band at 1179,1403 , and $1467 \mathrm{~cm}^{-1}$ may be attributed to $\mathrm{C}-\mathrm{C}$ bending; and absorption band at 2845 and $2915 \mathrm{~cm}^{-1}$ might be related to C-H stretching, as described elsewhere $[18,22]$.

The peak intensity of PVDF-60 is unique. The value is higher at $\mathrm{C}-\mathrm{C}$ bending but weaker at $\mathrm{C}-\mathrm{H}$ stretching. This may explain the presence of different crystal types most likely attributed by imperfect crystallization representing bending of PVDF back-bond not in an ideal crystal shape.

Results from XRD in Figure 6 show that all the membranes exhibit the same XRD diffraction pattern with minor difference in intensity at certain peaks. As reported earlier, time and temperature of crystallization are factors that determine the predominant phase of crystal [23]. Although the dope solution temperature was varied, the applied range $\left(25\right.$ to $100^{\circ} \mathrm{C}$ ) seems not wide enough to notice the obvious change of the PVDF crystal structure in the membrane matrix. However, Figure 6 shows that PVDF-60 has a less $\alpha$-phase structure at $20^{\circ}$. Since $\beta$-phase is most stable at $60^{\circ} \mathrm{C}$, the transformation of $\alpha$ - to $\beta$-phase occurs efficiently at this temperature compared to others $[23,24]$, thus explaining the low intensity of $\alpha$-phase obtained by PVDF- 60 . Considering its low total crystallinity (Table 2), the difference of peak intensity of $\beta$-phase could not be observed.

Figure 6 (inset) illustrates the XRD results of selected membranes (dope solutions of 40,60 , and $80^{\circ} \mathrm{C}$ ) penetrated at the top surface layer. The findings support the result obtained in Figure 6 by showing that PVDF-60 has the highest peak intensity of $\beta$-phase $[19,25]$. At $20.1^{\circ}$ which indicate predominant formation of $\alpha$-phase, PVDF- 80 shows the highest intensity. It is in line with a study by Gregorio and Cestari [23] that suggests that $\alpha$-phase is stable at the range of $80-160^{\circ} \mathrm{C}$. The predominance of $\beta$-phase in PVDF- 60 might be attributed to the formation of more imperfect crystal in the membrane matrix (Figure 4).

3.2. Short-Term DCMD Performance. Synthetic seawater (Figure 7) and brine (Figure 8) were used as feeds to assess the flux performance of the developed membranes. From the permeation test, the flux and rejection trends of the samples are almost the same for both feeds and both membrane orientations. However, a small decrease of flux is detected when brine is used as the feed instead of seawater for both membrane orientations. This is because the higher salinity in brine depresses the vapor pressure in the feed which acts as driving force in $\mathrm{MD}[20,26]$.

Figure 7 shows that the maximum flux of $181 / \mathrm{m}^{2} \mathrm{~h}$ was obtained by PVDF-60, when seawater was used as the feed. The value is considerably high for the given feed $\left(65^{\circ} \mathrm{C}\right)$ and permeate side $\left(25^{\circ} \mathrm{C}\right)$ temperatures for both top layer facing the feed (Figures $7(\mathrm{a})$ and $8(\mathrm{a})$ ) and top layer facing permeate side (Figures $7(\mathrm{~b})$ and $8(\mathrm{~b})$ ) orientations. The maximum flux obtained by PVDF-60 can be ascribed to its low thickness and low crystallinity due to formation of imperfect crystal and due to its desirable pore size distribution as discussed in Section 3.1.2. The presence of imperfect crystalline structures helps to improve MD flux, especially under the top membrane surface facing the hot feed orientation 


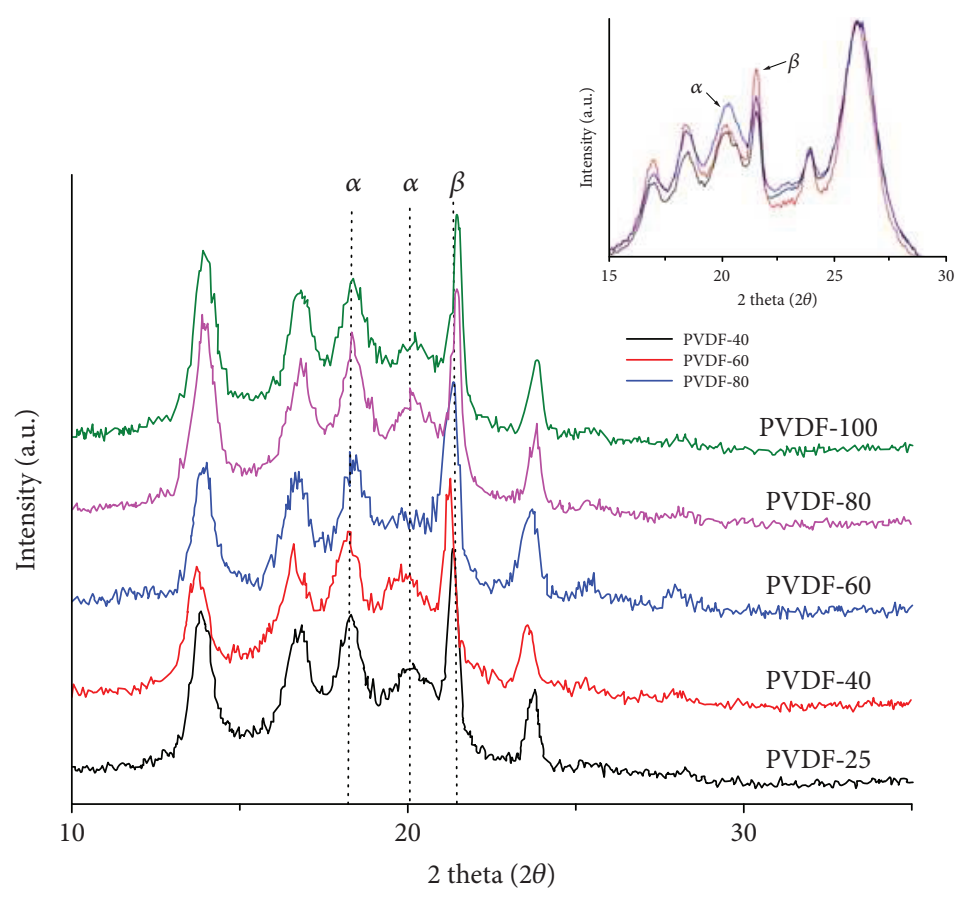

FIGURE 6: XRD (stacked) spectra of the PVDF membranes. The inset shows the spectra of selected membranes specifically obtained for a thin layer near the top surface.

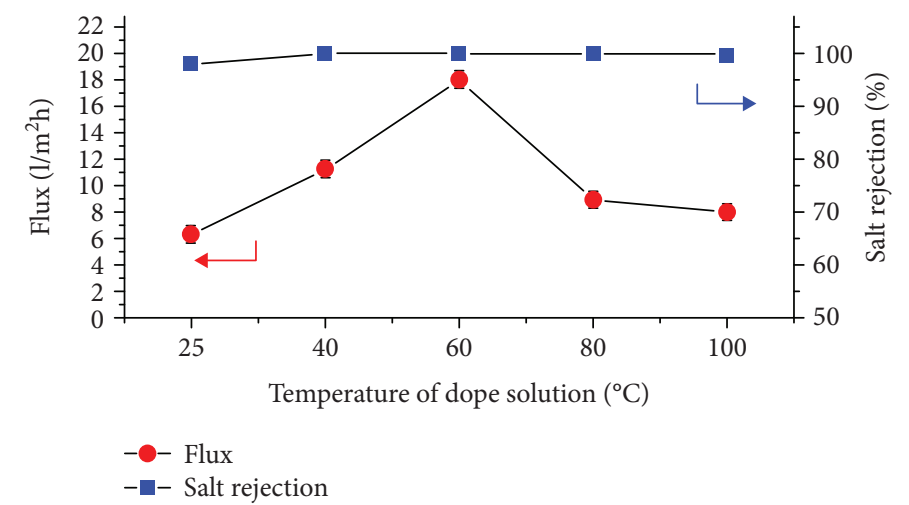

(a) Top

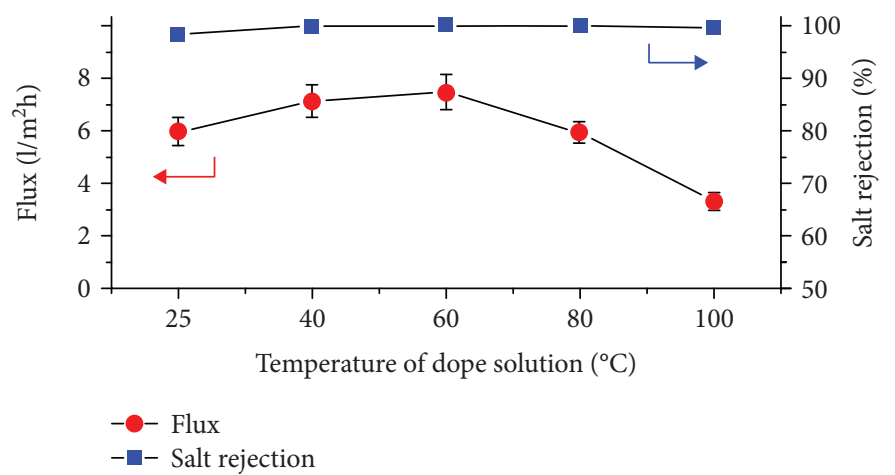

(b) Bottom

Figure 7: Flux and salt rejection of resulting membranes positioned under the (a) top layer facing feed and (b) top layer facing permeate. The tests were performed using seawater at $65^{\circ} \mathrm{C}$ as the feed and cold side temperature of $25^{\circ} \mathrm{C}$. 


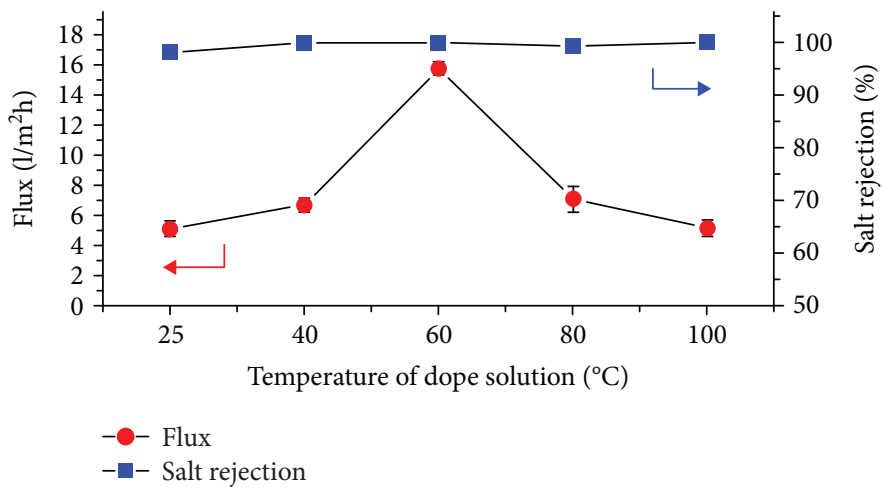

(a) Top

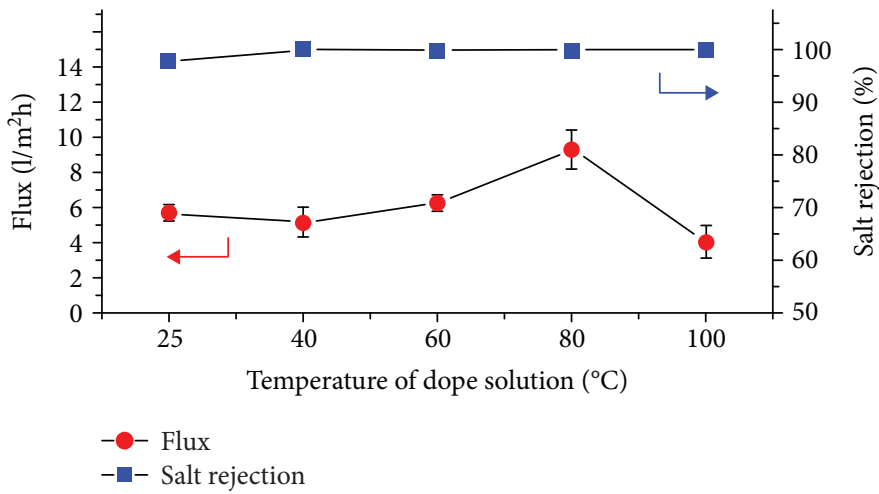

(b) Bottom

FIgURE 8: Flux performance and salt rejection of the resulting membranes using brine as the feed. The membranes were positioned under the (a) top layer facing feed and (b) top layer facing permeate.

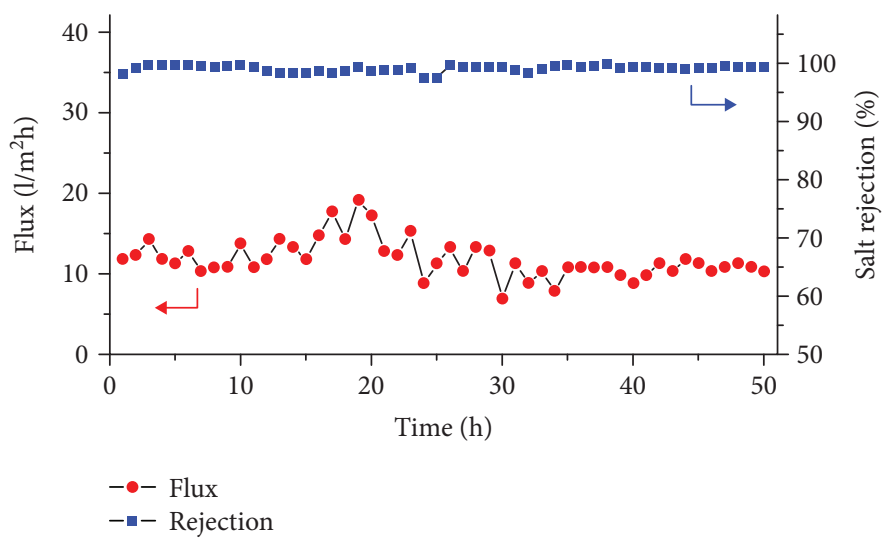

FIGURE 9: Long-term MD performance of PVDF-60 for treating brine as a feed flux and rejection. The feed and cold temperature was $65^{\circ} \mathrm{C}$ and $25^{\circ} \mathrm{C}$, respectively. The membrane was positioned in the top surface facing feed configuration.

(Figure $7(\mathrm{a})$ ). Low crystallinity favors free space for water vapor to pass by. It can then further decrease tortuosity property, thanks to a low crystallinity from an imperfect crystalline structure.

In addition, the orientation of the top surface layer also affects the flux performance of the resulting membranes. From the permeation results, the trend shows that the fluxes obtained are always lower when the top layer facing permeate orientation was applied instead of the top layer facing feed. Referring to prior discussions in Section 3.1, the rapid solidification process at the membrane top layer provides more time for crystallization to take place at the bottom layer, thus resulting in denser structures and responsible for flux decrement. Hence, the orientation of the membrane's top layer in DCMD is important because of the morphological difference between the top and bottom layers.

The lowed flux exhibited by other membranes can be ascribed by partial pore wetting, particularly for PVDF-25 ascribed from its poor salt rejection. The wetted pores become untenable for transport and inhibit the transport of 
water vapor and reduce the flux. When a complete pore wetting occurs, it facilitates salt bridging that deteriorates salt rejection. The PVDF-25 has the lowest salt rejection value than the rest. Pore wetting lowers water flux by decreasing the temperature gradient. This happens because the penetrant liquid in the pore is static inaccessible from external mixing. It is worth noting that these results were obtained during a short-term test and should be confirmed via a long-term test discussed in Section 3.3.

When compared with recent literature, the flux of our membranes (even for the most optimum one) is considered low [7, 27-33]. However, the flux value is not only a function of intrinsic membrane properties. Our low flux value is due to our low applied crossflow velocities, limited by our experimental set-up.

3.3. Long-Term Performance (Wetting Resistance Test). A long-term permeability test has been conducted to determine the capability of the developed membrane to retain their performance stability in term of flux and salt rejection. Considering the optimum flux in the short-term test (Section 3.2) was obtained by PVDF-60 under the top layer facing feed orientation, it has been selected for the long-term test. Figure 9 shows the trends of water flux and solute rejection of PVDF60 during $50 \mathrm{~h}$ operation by using synthetic brine as the feed. Both the flux and the salt rejection are quite stable during the entire testing period with flux average of $10.51 / \mathrm{m}^{2} \mathrm{~h}$ and salt rejection of $>99 \%$, which proves that PVDF- 60 possesses a high wetting resistance. The flux is also highly encouraging, $50 \%$ higher than the one obtained for the corrugated PVDF membrane reported elsewhere [31]. Relatively high MD flux offered by PVDF-60 is attributed from its lower crystallinity that increases the free volume (voids) in the polymer matrix and thus facilitates the transport of water vapor.

The flux obtained by this test, nevertheless, is still lower than the ones obtained in the short-term DCMD test (Figures 7 and 8). This might be due to the temperature polarization since DCMD configuration was used. The decrement of temperature differences across the membrane eventually reduces the rate of water vapor transportation.

\section{Conclusion}

Manipulating dope solution temperature was found effective to increase PVDF MD membrane performance, being optimum at $60^{\circ} \mathrm{C}$. It offers considerably high steady state flux $\left(18.5 \mathrm{l} / \mathrm{m}^{2} \mathrm{~h}\right)$ and high wetting resistance over long-term operation $(50 \mathrm{~h})$. The gain on MD performance for PVDF60 can be ascribed from its low thickness, desirable pore size distribution, and most importantly, low crystallinity that offers high free space for water vapor to pass by. The combination of the aforementioned factors leads to improvements of the mass transfer across the membrane.

\section{Data Availability}

The data used to support the findings of this study are included within the article.

\section{Additional Points}

Highlights. The role of dope solution temperature on PVDF crystallization was explored. An optimum temperature of $60^{\circ} \mathrm{C}$ helps to reduce PVDF crystallization. Crystallization was reduced via formation of imperfect crystal. The optimum dope solution temperature was $60^{\circ} \mathrm{C}$ in terms of improved MD performance.

\section{Conflicts of Interest}

The authors declare that they have no conflicts of interest.

\section{Acknowledgments}

We acknowledge Yayasan Universiti Teknologi PetronasMalaysia for providing grants (Grant number: 0153AA-E96) and the Chemical Engineering Department for providing facilities for conducting the research activities.

\section{References}

[1] A. Alkhudhiri, N. Darwish, and N. Hilal, "Membrane distillation: a comprehensive review," Desalination, vol. 287, pp. $2-$ $18,2012$.

[2] M. C. García-Payo, M. A. Izquierdo-Gil, and C. FernándezPineda, "Wetting study of hydrophobic membranes via liquid entry pressure measurements with aqueous alcohol solutions," Journal of Colloid and Interface Science, vol. 230, no. 2, pp. 420-431, 2000.

[3] L. D. Tijing, Y. C. Woo, J.-S. Choi, S. Lee, S.-H. Kim, and H. K. Shon, "Fouling and its control in membrane distillation-a review," Journal of Membrane Science, vol. 475, pp. 215-244, 2015.

[4] R. W. Schofield, A. G. Fane, and C. J. D. Fell, "Heat and mass transfer in membrane distillation," Journal of Membrane Science, vol. 33, no. 3, pp. 299-313, 1987.

[5] N. N. Li, A. G. Fane, W. W. Ho, and T. Matsuura, Advanced Membrane Technology and Applications, John Wiley \& Sons, 2011.

[6] G.-D. Kang and Y.-M. Cao, "Application and modification of poly(vinylidene fluoride) (PVDF) membranes-a review," Journal of Membrane Science, vol. 463, pp. 145-165, 2014.

[7] F. A. AlMarzooqi, M. R. Bilad, and H. A. Arafat, "Development of PVDF membranes for membrane distillation via vapour induced crystallisation," European Polymer Journal, vol. 77, pp. 164-173, 2016.

[8] M. Peng, H. Li, L. Wu, Q. Zheng, Y. Chen, and W. Gu, "Porous poly(vinylidene fluoride) membrane with highly hydrophobic surface," Journal of Applied Polymer Science, vol. 98, no. 3, pp. 1358-1363, 2005.

[9] H. Fan, Y. Peng, Z. Li, P. Chen, Q. Jiang, and S. Wang, "Preparation and characterization of hydrophobic PVDF membranes by vapor-induced phase separation and application in vacuum membrane distillation," Journal of Polymer Research, vol. 20, no. 6, p. 134, 2013.

[10] Y. Peng, H. Fan, Y. Dong, Y. Song, and H. Han, "Effects of exposure time on variations in the structure and hydrophobicity of polyvinylidene fluoride membranes prepared via vaporinduced phase separation," Applied Surface Science, vol. 258, no. 20 , pp. 7872-7881, 2012. 
[11] M. G. Buonomenna, P. Macchi, M. Davoli, and E. Drioli, "Poly(vinylidene fluoride) membranes by phase inversion: the role the casting and coagulation conditions play in their morphology, crystalline structure and properties," European Polymer Journal, vol. 43, no. 4, pp. 1557-1572, 2007.

[12] X. Wang, L. Zhang, D. Sun, Q. An, and H. Chen, "Formation mechanism and crystallization of poly(vinylidene fluoride) membrane via immersion precipitation method," Desalination, vol. 236, no. 1-3, pp. 170-178, 2009.

[13] N. I. M. Nawi, M. R. Bilad, and N. A. H. M. Nordin, "Effect of dope solution temperature on the membrane structure and membrane distillation performance," IOP Conference Series: Earth and Environmental Science, vol. 140, article 012032, 2018.

[14] E. Pramono, A. Simamora, C. Radiman, and D. Wahyuningrum, "Effects of PVDF concentration on the properties of PVDF membranes," IOP Conference Series: Earth and Environmental Science, vol. 75, article 012027, 2017.

[15] K. Nakagawa and Y. Ishida, "Annealing effects in poly(vinylidene fluoride) as revealed by specific volume measurements, differential scanning calorimetry, and electron microscopy," Journal of Polymer Science Part A-2: Polymer Physics, vol. 11, no. 11, pp. 2153-2171, 1973.

[16] D. Hou, H. Fan, Q. Jiang, J. Wang, and X. Zhang, "Preparation and characterization of PVDF flat-sheet membranes for direct contact membrane distillation," Separation and Purification Technology, vol. 135, pp. 211-222, 2014.

[17] Z. Zhenxin and T. Matsuura, "Discussions on the formation mechanism of surface pores in reverse osmosis, ultrafiltration, and microfiltration membranes prepared by phase inversion process," Journal of Colloid and Interface Science, vol. 147, no. 2, pp. 307-315, 1991.

[18] H. Bai, X. Wang, Y. Zhou, and L. Zhang, "Preparation and characterization of poly(vinylidene fluoride) composite membranes blended with nano-crystalline cellulose," Progress in Natural Science: Materials International, vol. 22, no. 3, pp. 250-257, 2012.

[19] J. Liu, X. Lu, and C. Wu, "Effect of preparation methods on crystallization behavior and tensile strength of poly(vinylidene fluoride) membranes," Membranes, vol. 3, no. 4, pp. 389-405, 2013.

[20] L. Eykens, I. Hitsov, K. De Sitter et al., "Influence of membrane thickness and process conditions on direct contact membrane distillation at different salinities," Journal of Membrane Science, vol. 498, pp. 353-364, 2016.

[21] M. Zhang, A.-Q. Zhang, B.-K. Zhu, C.-H. Du, and Y.-Y. Xu, "Polymorphism in porous poly(vinylidene fluoride) membranes formed via immersion precipitation process," Journal of Membrane Science, vol. 319, no. 1-2, pp. 169-175, 2008.

[22] A. Bottino, G. Camera-Roda, G. Capannelli, and S. Munari, "The formation of microporous polyvinylidene difluoride membranes by phase separation," Journal of Membrane Science, vol. 57, no. 1, pp. 1-20, 1991.

[23] J. R. Gregorio and M. Cestari, "Effect of crystallization temperature on the crystalline phase content and morphology of poly(vinylidene fluoride)," Journal of Polymer Science Part B: Polymer Physics, vol. 32, no. 5, pp. 859-870, 1994.

[24] R. Gregorio, "Determination of the $\alpha, \beta$, and $\gamma$ crystalline phases of poly(vinylidene fluoride) films prepared at different conditions," Journal of Applied Polymer Science, vol. 100, no. 4, pp. 3272-3279, 2006.
[25] S. Rajabzadeh, T. Maruyama, Y. Ohmukai, T. Sotani, and H. Matsuyama, "Preparation of PVDF/PMMA blend hollow fiber membrane via thermally induced phase separation (TIPS) method," Separation and Purification Technology, vol. 66, no. 1, pp. 76-83, 2009.

[26] I. Hitsov, L. Eykens, W. D. Schepper, K. D. Sitter, C. Dotremont, and I. Nopens, "Full-scale direct contact membrane distillation (DCMD) model including membrane compaction effects," Journal of Membrane Science, vol. 524, pp. 245-256, 2017.

[27] L. Zheng, J. Wang, J. Li, Y. Zhang, K. Li, and Y. Wei, "Preparation, evaluation and modification of PVDF-CTFE hydrophobic membrane for MD desalination application," Desalination, vol. 402, pp. 162-172, 2017.

[28] S. Munirasu, F. Banat, A. A. Durrani, and M. A. Haija, "Intrinsically superhydrophobic PVDF membrane by phase inversion for membrane distillation," Desalination, vol. 417, pp. 77-86, 2017.

[29] D. Singh and K. K. Sirkar, "Performance of PVDF flat membranes and hollow fibers in desalination by direct contact membrane distillation at high temperatures," Separation and Purification Technology, vol. 187, pp. 264-273, 2017.

[30] L. Eykens, K. De Sitter, C. Dotremont, L. Pinoy, and B. Van der Bruggen, "Characterization and performance evaluation of commercially available hydrophobic membranes for direct contact membrane distillation," Desalination, vol. 392, pp. 6373, 2016.

[31] M. R. Bilad, E. Guillen-Burrieza, M. O. Mavukkandy, F. A. Al Marzooqi, and H. A. Arafat, "Shrinkage, defect and membrane distillation performance of composite PVDF membranes," Desalination, vol. 376, pp. 62-72, 2015.

[32] J. A. Kharraz, M. R. Bilad, and H. A. Arafat, "Flux stabilization in membrane distillation desalination of seawater and brine using corrugated PVDF membranes," Journal of Membrane Science, vol. 495, pp. 404-414, 2015.

[33] D. Sun, M.-Q. Liu, J.-H. Guo, J.-Y. Zhang, B.-B. Li, and D.-Y. Li, "Preparation and characterization of PDMS-PVDF hydrophobic microporous membrane for membrane distillation," Desalination, vol. 370, pp. 63-71, 2015. 


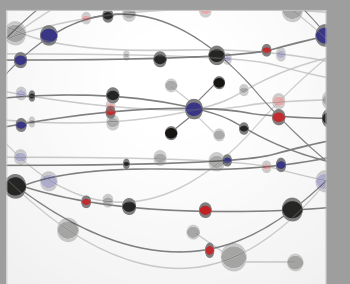

The Scientific World Journal
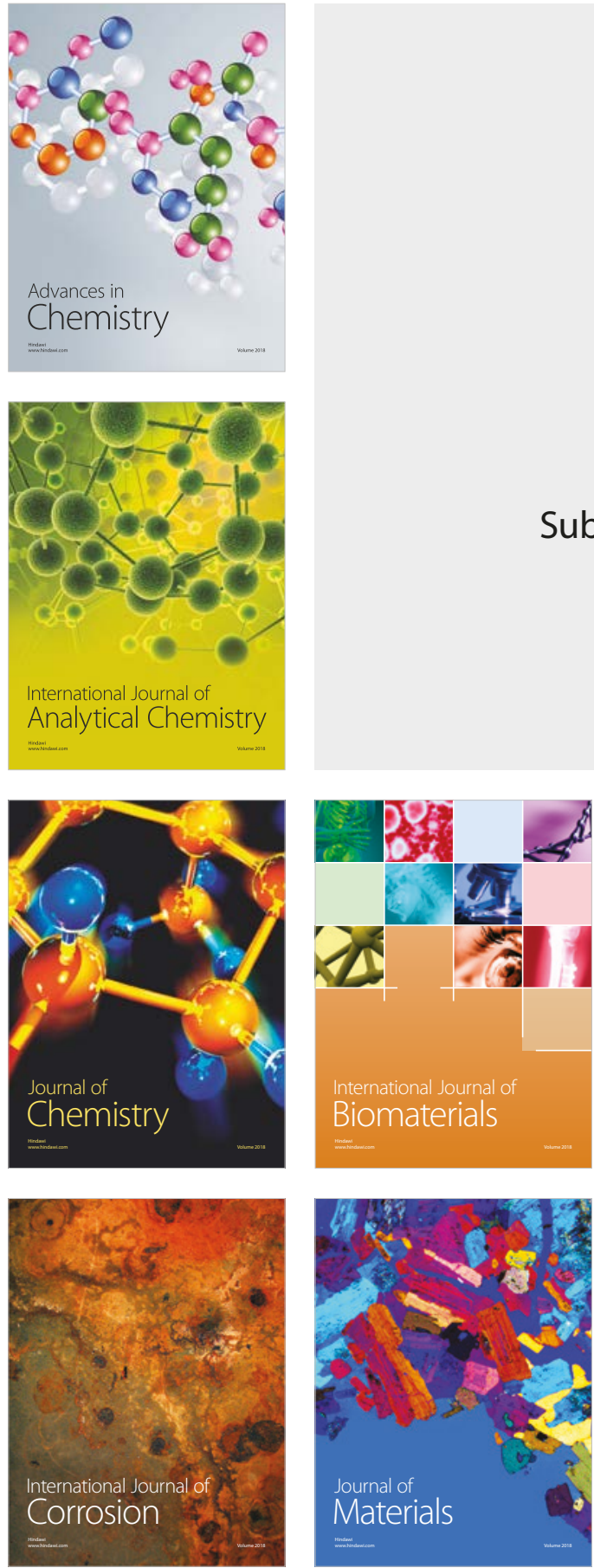

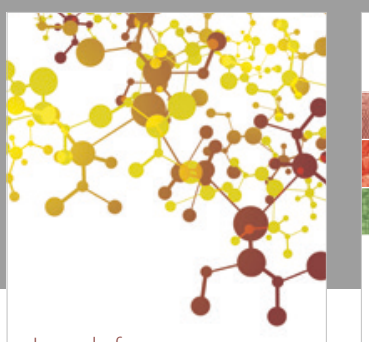

Journal of

Applied Chemistry
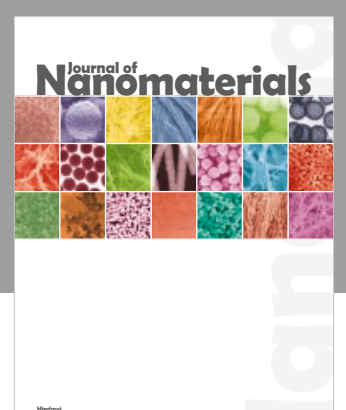

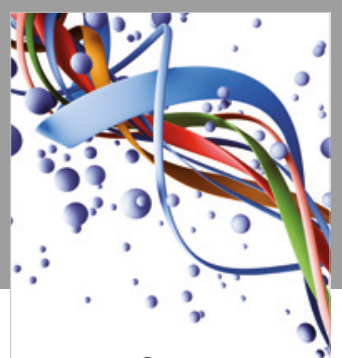

Scientifica

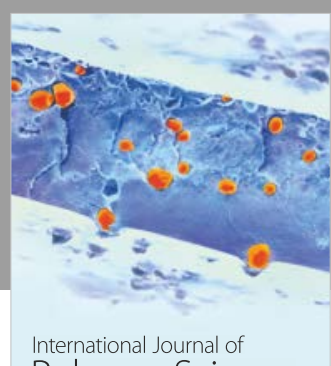

Polymer Science

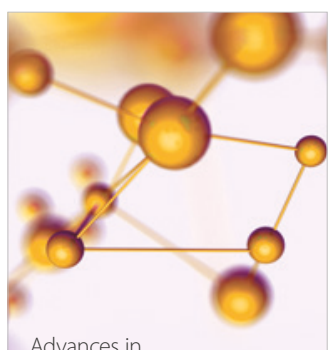

Physical Chemistry
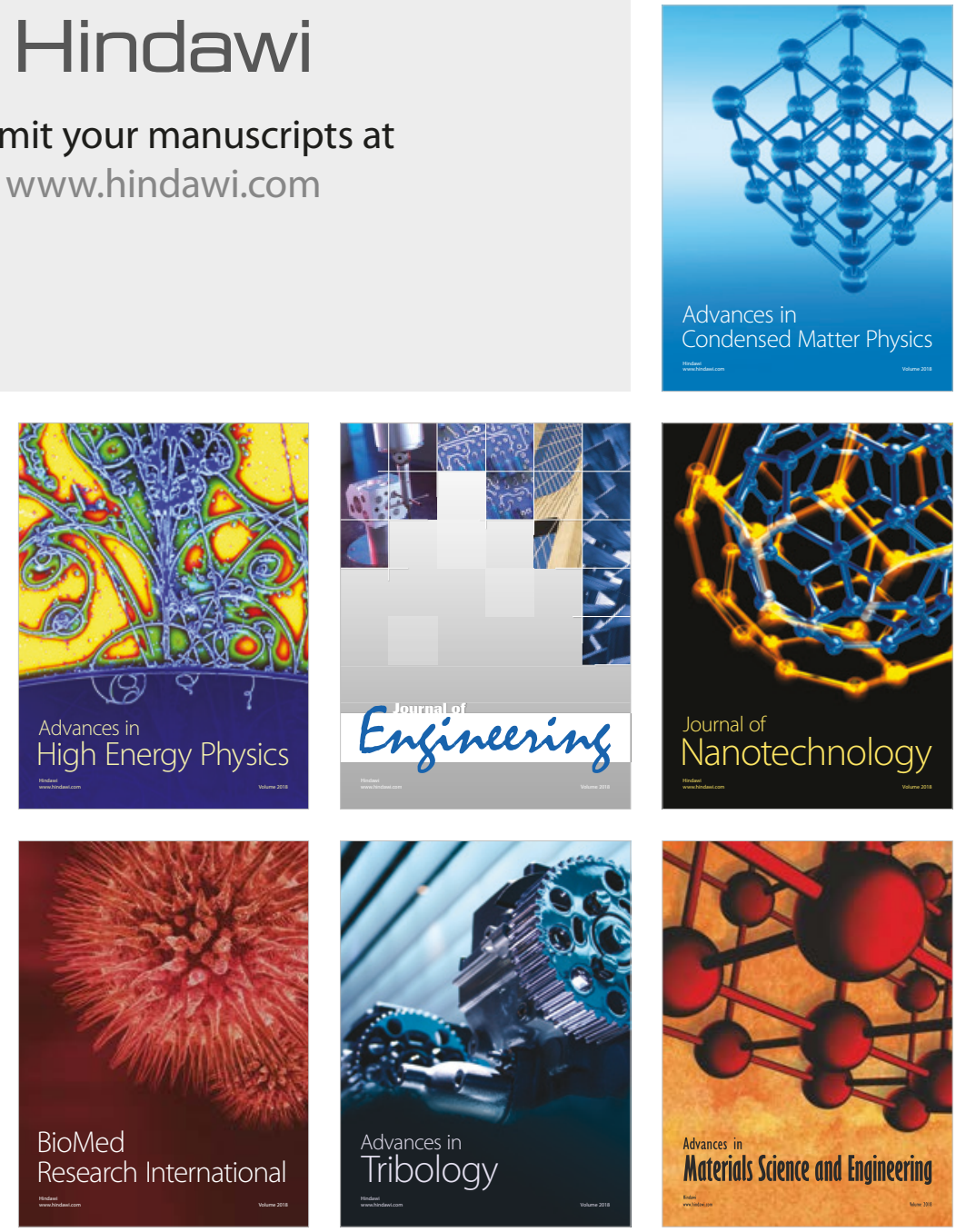